\title{
Penetrating Abdominal Trauma: Experience in a Teaching Hospital, Calabar, Southern Nigeria
}

\author{
Maurice Asuquo, Mark Umoh, Victor Nwagbara, Gabriel Ugare, Cyril Agbor, Emmanuel Japhet \\ Department of Surgery, University of Calabar Teaching Hospital, Calabar, Nigeria. \\ Email: mauefas2@yahoo.com, imezuma@yahoo.com, aikay_en@yahoo.com, udeyhenugare@yahoo.com, \\ cyrilagbor07@yahoo.com,owoden_eyaaah@yahoo.com
}

Received May 28 ${ }^{\text {th }}$, 2012; revised June $30^{\text {th }}$, 2012; accepted July $15^{\text {th }}, 2012$

\begin{abstract}
Background: Penetrating abdominal trauma (PAT) typically involves the violation of the abdominal cavity by a gunshot wound (GSW) or stab wound. Recently several studies have favored a more conservative approach as opposed to mandatory exploratory laparotomy. Methods: Patients admitted in the University of Calabar Teaching Hospital (UCTH), Calabar, with PAT from January 2008 to December 2010 were prospectively studied based on a questionnaire. The total number of patients with PAT was compared with total number of emergencies, traumatic injuries and abdominal trauma seen during the same period. Results: A total of 48 patients presented with abdominal trauma: PAT 29 (60\%) and blunt abdominal trauma (BAT) 19 (40\%). The ages of the patients (28 male, 1 female) ranged from 3 - 62 years (mean 28.1 years). Gunshot wound (GSW) 11 (38\%) patients, stab wound 8 (27.6\%) patients and machete cut 4 (13.8\%) patients ranked first, second and third respectively as causes of PAT. The commonest organ injury was perforation of the small intestine. Four (13.8\%) patients were managed conservatively while 25 (86.2\%) patients had laparotomy. The duration of admission ranged from 2 - 19 days (mean 10.5 days). Morbidity [surgical site infection (SSI)] and mortality were recorded in 2 (6.9\%) and $3(10.3 \%)$ patients respectively. Conclusion: Key areas that require attention have been highlighted. Revamping the ailing economy and gainful employment for youths are paramount areas that require prompt, dedicated and sustained intervention for reduction in violent crimes.
\end{abstract}

Keywords: Penetrating Abdominal Trauma; Pattern; Management

\section{Introduction}

Penetrating abdominal trauma (PAT) typically involves the violation of the abdominal cavity by a gunshot wound (GSW) or stab wound [1,2]. The frequency of PAT across the globe relates to industrialization of developing nations, weapons available and significantly to the presence of military conflicts. Therefore the frequency varies $[2,3]$.

Baudens ML performed the first exploratory laparotomy for trauma. Management has gone full cycle from exploration for all cases of penetrating trauma to the present maxim that "not everybody with a hole in the abdomen needs exploration" [4,5]. The mandate for surgical exploration for all PAT has been questioned [6]. In 1960, Shaftan suggested selective management of patients with abdominal stab wound after observing an increased rate of laparotomy without identifiable injuries [2]. Recently several studies have favored a more conservative approach as opposed to mandatory exploratory laparotomy [7,8]. More recently, expectant management has been used in the treatment of specific GSW's to the abdomen [2,3].

Effective policies on safety should be developed based on evidence of local research and not on adapted models. This study presents the current study of PAT characteristics to highlight areas that require attention and proffer solutions for prevention.

\section{Patients and Methods}

Pre-hospital interventions are not in place in our setting as there are no ambulance/paramedic services. There is no organized trauma team at reception yet, doctors and nurses trained in accident and emergency receive the injured at the reception bay. Primary survey/resuscitation is carried out; thereafter the patients are referred to the surgical unit on call based on the specialty/specialties required.

The first on call is the registrar, followed by the senior registrar (mostly pre-fellowship) and the consultant surgeon. Anesthesiology is organized in a similar pattern. There is a theatre dedicated for emergencies and a three bed intensive care unit. 
Patients admitted in the UCTH, Calabar with PAT from January 2008 to December 2010 were prospectively studied based on a questionnaire. This included biographic data, mechanism and circumstance of injuries, injured organs, duration of admission, as well as associated injuries. Others included management and outcome.

Patients were categorized into two groups: operative (laparotomy) and non-operative management (NOM). The latter group is defined as patients with PAT without peritonitis, heamodynamic stability without high spinal cord or severe head injury. The policy of selective NOM requires serial physical abdominal examination to rule out hemorrhage and peritonitis. Failed NOM was defined as patient who ultimately requires surgical exploration.

The total number of patients with PAT was compared with total number of emergencies, traumatic injuries and abdominal trauma seen during the same period. This was also compared with an earlier study of PAT (2005-2007).

\section{Results}

During the study period of 3 years (2008-2010), a total of 12,083 patients presented to the accident and emergency department of the University of Calabar Teaching Hospital, Calabar. In the same period, 4942 (41\%) trauma patients were seen, of this, 48 (1\%) suffered abdominal injury: PAT 29 (60\%) and BAT (19 (40\%). In the previous 3 years of this prospective study (2005-2007), the 79 abdominal trauma patients seen accounted for $4.8 \%$ of trauma cases: PAT 39 (49\%) and BAT 40 (51\%).

The ages of the patients (28 male, 1 female) ranged from 3 - 62 years (mean 28.1 years). During the $1^{\text {st }}$ decade, the three children recorded suffered injuries due to falls, the frequency increased to a peak in the $3^{\text {rd }}$ decade due to violent activities (stab, machete and gunshot injuries). There was a decline from the $4^{\text {th }}$ to the $7^{\text {th }}$ decades,

Figure 1. Four patients in the $5^{\text {th }}-7^{\text {th }}$ decades suffered

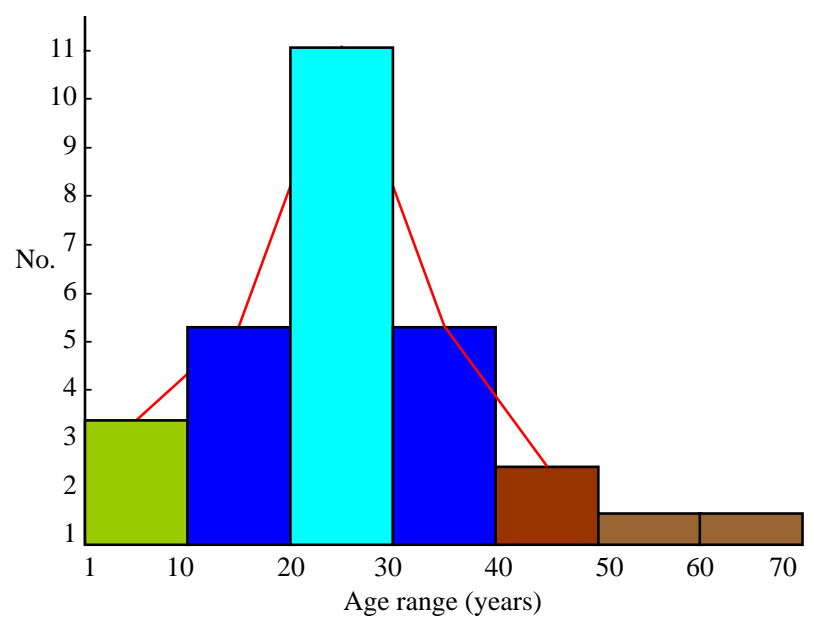

Age range: 3 - 6 years, (means 28.1years).

Figure 1. Age distribution. gunshot injuries from robbers.

Table 1 shows the distribution of the type of injury. Gunshot wounds were the commonest injury that involved 11 (38.0\%) patients. This compares with the previous study (2005-2007), GSW afflicted 15 (38.5\%) patients, Stab wound ranked second 8 (27.6\%), and this showed a contrast with the previous study (2005-2007) that recorded 18 (46.1\%) patients. Others were machete cut 4 (13.8\%), falls and road traffic accident 3 (10.3\%) each. Violent crime (stab wound, machete cut, GSW) were recorded in 23 (79.4\%) patients while 2005-2007 showed 33 (84.6\%) patients. The only female sustained stab wound. The offending agents in stab wounds were broken bottles and knives. The circumstances of GSW were attacks by robbers and from police. The 3 children recorded in this study fell on sharp objects (broken bottles, sharp stick).

The commonest organ injury was perforation of the small intestine 12 (37.5\%) while evisceration of omentum/small intestine ranked second 9 (28\%), Figures 2 and 3. Others were perforation of the stomach $3(9.4 \%)$, spleen 3 (9.4\%). Two (6.3\%) patients each suffered injuries to the mesentery/colon and a patient (3.1\%) with renal injury, Table 2. The commonest region with associated injuries was the chest 3 (37.5\%), Table 2 .

Table 1. Type of injury.

\begin{tabular}{lcc}
\hline Type of injury & $\begin{array}{c}\text { No. (\%) } \\
(\mathbf{2 0 0 8 - 2 0 1 0 )}\end{array}$ & $\begin{array}{c}\text { No. (\%) } \\
(\mathbf{2 0 0 5}-\mathbf{2 0 0 7})\end{array}$ \\
\hline Stab injury & $8(27.6)$ & $18(46.1)$ \\
Machete cut & $4(13.8)$ & - \\
Gunshot & $11(38.0)$ & $15(38.5)$ \\
Fall & $3(10.3)$ & $1(2.6)$ \\
Road traffic accident & $3(10.3)$ & $2(5.1)$ \\
Work related-cow horn & - & $2(5.1)$ \\
injury/shrapnel & - & $1(2.6)$ \\
Criminal abortion (impalement Injury) & $-39(100)$ \\
\hline
\end{tabular}

*Violent crime (Stab injury, machete cut, gunshot): 23 (79.4), 33 (84.6).

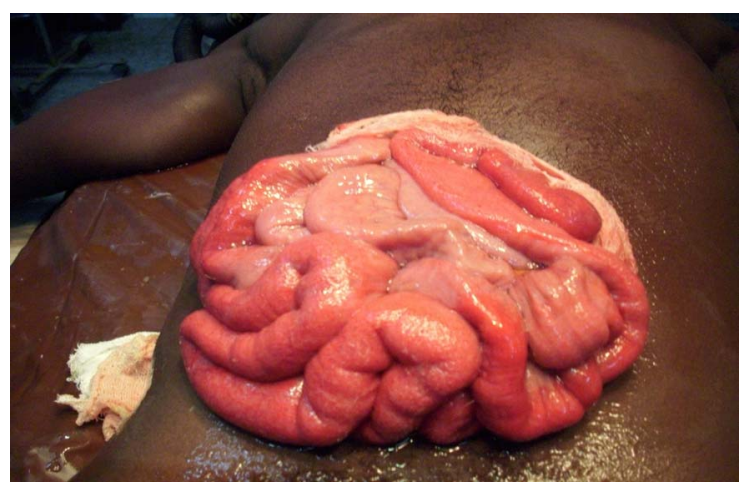

Figure 2. Clinical photograph-showing prolapsed small intestine (stab wound). 
The patients were categorized into two groups for management: operative (laparotomy) 25 (86.2\%) and non-operative 4 (13.8\%). In the latter, the 4 male patients (stab wounds) whose ages ranged from $18-27$ years (mean 23.5 years) were managed with satisfactory (wounds healed) outcomes. In the laparotomy group (25) patients: one had a negative laparotomy while the outcomes in 21 were satisfactory. The morbidity and mortality profile is shown in Table 3 . The duration of admission ranged from 2 - 19 days (mean 10.5 days). Two (6.9\%) patients who suffered stab injuries developed surgical site infection (SSI), this was responsible for increased duration of admission. Three (10.3\%) patients inflicted with gunshot injuries that resulted in colonic, splenic/renal injuries had fatal outcome, Table 3.

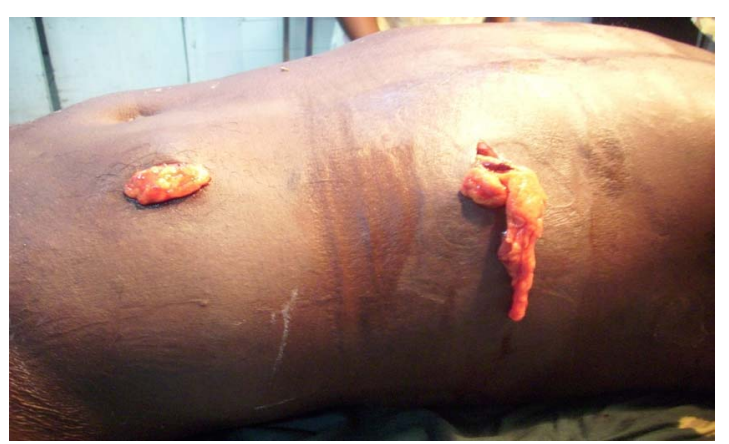

Figure 3. clinical photograph-showing prolapsed omentum (gunshot wound).

\section{Discussion}

Despite the decline in the number of PAT patients when compared to our previous study [3], PAT now accounts for $60 \%$ of abdominal trauma probably due to a decline in BAT cases consequent upon the ban on motorcycle use in Calabar. Osime and Oludiran in Benin, Southern Nigeria [1] reported 34 cases of PAT in 10 years; this is lower when compared to our report. In another report from southwest Nigeria, Ayode et al. [9] reported BAT $79.2 \%$, PAT $20.8 \%$ in keeping with our previous report [3]. However, penetrating abdominal injuries appear to be on the increase in Nigeria $[8,10]$. This trend has also been observed worldwide possibly due to increase in interpersonal violence throughout the world [11,12]. In Kano, a populated urban area in Northern Nigeria, Edino ST [13] reported PAT 53.7\%, BAT $46.3 \%$ in keeping with our recent experience.

Males constitute the great majority of patients with penetrating trauma injuries across the United States, approximately $90 \%$ of patients with penetrating trauma are male [2]. This compares with our finding (96.6\%), Osime and Oludiran reported 88.2\% [1]. They constitute an active aggressive segment of the population and more often involved in acts of violence [3]. This is aggravated by the high level of unemployment.

Osime and Oludiran showed that 21 - 30 year age group was the most vulnerable (41.2\%) [1], Navsaria et $a l$. mean age of 29.5 years [14]. Males in this age group

Table 2. Organ/Associated injury.

\begin{tabular}{lcl}
\hline Injured organ & No. (\%) & Associated injury No. (\%) (Region) \\
\hline Evisceration of omentum/intestine & $9(28)$ & Head (laceration) 2 (25.0) \\
Stomach & $3(9.4)$ & Chest (laceration/haemothorax/pneumothorax) $3(37.5)$ \\
Spleen & $3(9.4)$ & Upper limb (laceration) 2 (25) \\
Small intestine (perforation) & $12(37.5)$ & Lower limb (pellets/punctures) 1 (12.5) \\
Mesentery & $2(6.3)$ & \\
Descending/sigmoid colon & $2(6.3)$ & \\
Renal & $1(3.1)$ & $8(100)$ \\
& $32(100)$ & \\
\hline
\end{tabular}

*1 patient had negative laparotomy; 3 patients had multiple organ injuries (gunshot).

Table 3. Morbidity/Mortality

\begin{tabular}{|c|c|c|c|c|c|c|}
\hline S/No. & Type of injury & Age (years) & Sex & Finding at operation & Treatment & $\begin{array}{l}\text { Outcome/duration } \\
\text { of admission }\end{array}$ \\
\hline 1. & Gunshot & 38 & M & Splenic/renal injury & $\begin{array}{l}{ }^{*} \text { Splenectomy } \\
{ }^{*} \text { Left partial nephrectomy }\end{array}$ & Fatal (Shock)/1 day \\
\hline 2. & Gunshot & 17 & M & Perforated descending colon & Colostomy & Fatal (Shock)/2 days \\
\hline 3. & Gunshot & 27 & M & Perforated sigmoid colon & Resection/anastomosis & Fatal (Shock)/2 days \\
\hline 4. & Stab injury & 30 & M & $\begin{array}{l}{ }^{*} \text { Moderate haemoperi-tonium } \\
{ }^{*} \text { Jejunal perforation } \\
{ }^{*} \text { Omental injury }\end{array}$ & $\begin{array}{l}{ }^{*} \text { Closure of perforation } \\
{ }^{*} \text { Partial omentectomy }\end{array}$ & $\begin{array}{l}{ }^{*} \text { Chest infection } \\
{ }^{*} \text { Surgical site infection } \\
\text { (SSI)/19 days }\end{array}$ \\
\hline 5. & Stab injury & 20 & M & $\begin{array}{l}{ }^{*} \text { Perforation of Ileum } \\
{ }^{*} \text { Pneumothorax }\end{array}$ & $\begin{array}{l}{ }^{*} \text { Closure of perforation } \\
{ }^{*} \text { Closed thoracostomy tube drainage (CTTD) }\end{array}$ & SSI/14 days \\
\hline
\end{tabular}

Mortality-10.3\%; SSI-6.9\%. 
generally are more aggressive in demonstrating resistance to perceived threat when compared to the very young and elderly [2,4]. This collaborates with our finding, Figure 1 (mean 28.1 years). It is rather disturbing as this age group constitutes the productive segment of the society and this impact negatively on the economy. Children in the first decade fell on sharp objects, proper care of children is recommended as this injury is avoidable.

Penetrating abdominal trauma may result from firearm, knives, broken glass pieces, $80 \%$ of penetrating injuries are due to firearm and $20 \%$ due to stab wound [15]. Our current experience revealed a peculiar pattern in the distribution of etiology, gunshot (38\%) ranked first followed by stab injury (27\%) while machete cut (13.8\%) was third, Table 1. Osime and Oludiran in Nigeria reported gunshot injuries as constituting $64.7 \%$ of cases [1]. When compared to our previous study [3], Table 1, there was a slight decline in GSW, a remarkable decrease in stab wounds. Efforts to sustain the downward trend by education against violent behavior would result in further decline in violent injuries. Perhaps, the decline may have been due to some patients presenting to other facilities in order to hide their identity and evade prosecution. Machete, a common farm implement has become an offending agent in our setting. Youths in the society move about with machete hidden under their clothing's [16]. Appropriate legislation and enforcement against the use of this weapon as offending agent is recommended. This is in addition to curbing illegal acquisition of firearms and other offending weapons, including strategies for peaceful co-existence and addressing issue of youth unemployment.

The commonest organ injury was perforation of the small intestine, while evisceration of omentum/small intestine ranked second. Other studies attest to this [9, 13,17]. This is not surprising as the small intestine occupies a large area of the abdominal cavity. Stab wounds are caused by penetration of the abdominal wall by sharp object. This type of wound generally has a more predictable pattern of organ injury. However, occult injuries can be overlooked resulting in devastating complications [2].

Some studies have advocated adoption of conservative management for penetrating abdominal injury especially when it is due to stab injury [18]. In deed some patients with stab injuries were successfully managed under the non-operative group with the attendant advantage of reduction in the number of laparotomy with its complications. Evisceration should continue to prompt operational intervention but exception can be made to a select few patients with omentum evisceration with benign abdominal findings $[19,20]$. Some of our patients attest to this.

Laparotomy for gunshot injuries in patients with severe injuries that resulted in shock was responsible for the fatal outcomes in our patients; splenectomy for shattered spleen (Type 1V) and renal injury, left colonic injuries (perforated descending and sigmoid colon). This is not surprising as the management of abdominal trauma hinges on the prevention of shock and infection (peritonitis), these when present, result in poor prognosis. In our setting where there is no pre-hospital treatment, no ambulance service, and sometimes-inadequate response to resuscitation and timely surgery, these factors affect negatively on the outcome.

Bowel injuries are a leading cause of morbidity and mortality following trauma [5]. The colon and small intestine were the most commonly injured organs and had the most postoperative complications [21]. In deed all our patients with fatal outcomes and surgical site infection suffered bowel injuries. We recorded 10.3\% mortality, this may be due to the fact that most severely injured die prior to hospitalization as there is no pre-hospital care in our setting. The average mortality rate for all patients with PAT is approximately 5\% in most level 1 trauma centers [2], Van Brussel and Van Hee reported 8.8\% [18]. Shock was responsible for the death in all the patients with fatal outcome. Death from refractory hemorrhagic shock or exsanguinations in the first 24 hours remains the most common cause of mortality [2].

In summary, PAT accounts for $60 \%$ of abdominal trauma. Males mainly in the third decade constitute the great majority of patients with PAT. Machete cut was peculiar in out setting and ranked third after gunshot and stab injuries that ranked first and second respectively. Bowel injuries were common injuries and accounted for morbidity and mortality. Non-operative management is safe for omental prolapse from stab injury with benign abdominal findings.

\section{Conclusion}

Key areas that require attention have been highlighted. No single solution exists for every hospital or community, individualization based on research findings is the key. Paramount importance must be placed on patient, family, community and support groups with interest in education which should be proactive in reduction of violent injury in our society. Revamping the ailing economy and gainful employment for youths remain as paramount areas that require prompt, dedicated and sustained intervention for reduction in violent crimes.

\section{REFERENCES}

[1] C. O. Osime and O. O. Oludiran, "Penetrating Abdominal Injury Cases Admitted in University of Benin Teaching Hospital,” Ann Biomed Sci, Vol. 3, No. 1-3, 2004, pp. 39-44.

[2] P. Offner, J. Geibel, K. J. Stanton-Maxe, H. S. Bjerke, et 
al., "Penetrating Abdominal Trauma,” 2012. http://emedicine.medscape.com/article/2036859

[3] M. E. Asuquo, O. O. Bassey, A. U. Etiuma, G. Ugare and N. Ogbu, “A Prospective Study of Penetrating Abdominal Trauma at the University of Calabar Teaching Hospital, Calabar, Southern Nigeria," European Journal of Trauma and Emergency Surgery, Vol. 35, No. 3, 2009, pp. 277280. doi:10.1007/s00068-008-8089-6

[4] W. Christensen, "Small Bowel and Mesentery," In: F. W. Blaisdell and D. D. Trunkey, Eds., Abdominal Trauma, Vol. 1, Thieme-Stratton, New York, 1982.

[5] A. E. Dongo, E. B. Kesieme, D. O. Irabor and J. K. Ladikpo, "A Review of Posttraumatic Bowel Injuries in Ibadan,” ISRN Surgery, 2011.

[6] W. W. Hope, S. T. Smith, B. Medieros, K. M. Hughes, C. A. Kotwall and T. V. Clancy, "Non-Operative Management in Penetrating Abdominal Trauma: Is It Feasible at a Level 11 Trauma Centre?” Emergency Medicine, 2011.

[7] P. Baker, "Penetrating Wounds of the Torso," Journal of the Royal Army Medical Corps, Vol. 147, No. 1, 2001, pp. 62-72.

[8] C. E. Ohanaka, P. C. Iribhoghe and R. O. Ofoegbu, "Gunshot Injuries in Benin City,” Nig J Surg Sci, Vol. 10, 2000, pp. 81-85.

[9] B. A. Ayoade, B. A. Salami, A. O. Tade, A. A. Musa and O. A. Olawoye, “Abdominal Injuries in Olabisi Onabanjo University Teaching Hospital, Sagamu, Nigeria,” Nigerian Journal of Orthopaedics and Trauma, Vol. 5, No. 2, 2006, pp. 45-49.

[10] C. Osime and J. Kpolugbo, "Penetrating Injuries in Irrua. A Sub-Urban Community in Nigeria," African Journal of Trauma, Vol. 2, No. 1, 2004, pp. 40-42.

[11] S. B. Naeder, "Pattern of Abdominal Injuries in Korle BU Teaching Hospital, Accra,” Ghana Medical Journal, Vol. 24, 1990, pp. 184-190.

[12] S. J. Mong, J. A. Lyle and M. Black, "A Review of Gunshot Deaths in Strathclyde 1989-1998,” Medicine, Science and the Law, Vol. 41, 2001, pp. 260-265.

[13] S. T. Edino, "Pattern of Abdominal Injuries in Aminu Kano Teaching Hospital, Kano,” Nigerian Postgraduate Medical Journal, Vol. 10, No. 1, 2003, pp. 56-59.

[14] P. H. Navsaria, J. U. Berli, S. Edu and A. J. Nicol, "NonOperative Management of Abdominal Stab Wounds: An Analysis of 186 Patients," South African Journal of Surgery, Vol. 45, No. 4, 2007; pp. 128-130.

[15] D. B. Hoyt and A. R. Mossa, “Abdominl Injuries,” In: A. Cuschieri, G. R. Giles, A. R. Mossa, Eds., Essential Surgical Practice, Vol. 3, Butter Worth Heinemann, Boston, 1995, pp. 531-544.

[16] M. Asuquo, V. Nwagbara, G. Ugare and A. Inyang, "Penetrating Abdominal Trauma," Nig J Surg Sci, Vol. 1, No. 2, 2005, pp. 47-50.

[17] D. V. Feliciano, J. M. Burch, V. Spjut-Patrinely, K. L. Mattox and G. L. Jordan Jr., "Abdominal Gunshot Wounds: An Urban Trauma Centre Experience with 300 Consecutive Patients,” Annals of Surgery, Vol. 208, No. 3, 1988, pp. 362-370. doi:10.1097/00000658-198809000-00014

[18] M. Van Brussel and R. Van Hee, "Abdominal Stab Wounds: A Five Year Patient Review,” European Journal of Emergency Medicine, Vol. 8, 2001, pp. 83-88. doi:10.1097/00063110-200106000-00002

[19] M. da Silva, P. H. Navsaria, S. Edu and A. J. Nicol, "Evisceration Following Stab Wounds: Analysis of 66 Cases,” World Journal of Surgery, Vol. 33, No. 2, 2009, pp. 215-219. doi:10.1007/s00268-008-9819-y

[20] D. L. Clarke N. L. Allorto and S. R. Thomson, “An Audit of Failed Non-Operative Management of Abdominal Stab Wounds,” Injury, Vol. 41, No. 5, 2010, pp. 488-491. doi:10.1016/j.injury.2009.10.022

[21] M. Saghafinia, N. Nafissi, M. R. K. Motamedi, et al., "Assesment and Outcome of 496 Penetrating Gastrointestinal Warfare Injuries,” Journal of the Royal Army Medical Corps, Vol. 156, No. 1, 2010, pp. 25-27. 